\title{
Educación \\ Sexual Integral \\ (ESI), varones y \\ masculinidades
}

\section{Lucas Pablo Serra \\ Universidad Nacional de Mar del Plata, Argentina \\ serralucaspablo@gmail.com}

\section{Resumen}

Tramas

En este artículo se presenta una indagación crítica en torno a la Educación Sexual Integral (ESI), los varones y las masculinidades. El trabajo analiza puntualmente los contenidos curriculares y materiales vigentes vinculados con la masculinidad, sus representaciones y marcos conceptuales en Argentina. El texto aborda los aspectos característicos del régimen de género escolar y su influencia en el proceso de construcción de la masculinidad entendida como dispositivo de poder orientado a la producción social de varones cis hetero. Finalmente, se presentan algunas líneas de debate en torno a las potencialidades de la ESI como instrumento para construir contra-pedagogías de la crueldad y como marco de exploración de prácticas colectivas que interpelan la masculinidad hegemónica y el régimen de género hetero cis normativo.

\section{Palabras clave}

1| Educación Sexual Integral 2| masculinidad hegemónica 3| régimen de género escolar 4| masculinidades $5 \mid$ contra-pedagogías

\section{Cita sugerida}

Serra, Lucas Pablo (2021). Educación Sexual Integral (ESI), varones y masculinidades. Tramas y Redes, (1), 103-120, 105a. DOI: 10.54871/cl4c105a 
Tramas

$\mathrm{N}^{0} 1$

ISSN en trámite

\title{
Educação Sexual Integral (ESI), homens e masculinidades
}

\begin{abstract}
Resumo
Neste artigo apresenta-se uma indagação critica em relação a Educação Sexual Integral (ESI), os homens e as masculinidades. A pesquisa analisou especialmente os conteúdos curriculares e materiais vigentes vinculados com a masculinidade, suas representações e marcos conceituais em Argentina. O texto aborda os aspectos caracterísiticos do régimen de gênero escolar e sua influência no processo de construção da masculinidade entendida como dispositivo de poder orientado na produção social de homens héterocis. Finalmente apresentam-se umas linhas no debate em relação as potencialidades da ESI como instrumento para a construção da contra-pedagogias da crueldade como marco de indagação de práticas coletivas interpeladoras da masculinidade hegemónica e o régimen de gênero héterocis normativo.
\end{abstract}

\section{Palavras chave}

1| Educação Sexual Integral 2| masculinidade hegemonica 3| régimen de gênero escolar 4| masculinidades $5 \mid$ contra-pedagogias

\section{Comprehensive Sexual Education, men and masculinities}

\begin{abstract}
This article presents a critical inquiry around Comprehensive Sexual Education (ESI, for its acronym in Spanish), men and masculinities. This work specifically analyzes curricular contents and current material related to masculinity, its representations and conceptual frameworks in Argentina. The text addresses the characteristic aspects of the school genre regime and its influence in the process of masculinity construction. This construction is considered as a powerful device orientated to the social production of cis gendered heterosexual men. Finally, some lines of debate are presented on the potential possibilities of the ESI as a tool to build counter-pedagogies of cruelty and as an experimental framework for collective practices questioning hegemonic masculinity and the cis gendered heterosexual normativity regime.
\end{abstract}

\section{Keywords}

1| Comprehensive Sexual Education 2| hegemonic masculinity 3| school genre regime 4| masculinities $\mathbf{5} \mid$ counter-pedagogies 
Los hombres están condenados, a partir de los trece o catorce años, a la pérdida del propio canto de sus emociones, de la emoción innata del afecto. La muda se añade a la separación del primer cuerpo. Pascal Quignard (2015, p. 35)

Los escenarios escolares y la tarea docente nos confrontan con situaciones dilemáticas que irrumpen espontáneas en la intemperie misma de la práctica cotidiana. La emergencia de estos fenómenos se produce en un territorio de disputas permanentes: la institución escolar. Las reflexiones que guían este texto se hallan organizadas en torno a la institución escolar como ámbito de debate y el vínculo problemático entre la Educación Sexual Integral y el campo de las masculinidades.

En las aulas, en los pasillos, en las reuniones de equipo, he oído (e incluso yo también lo he dicho seguramente) la pregunta: ¿qué hacemos con los varones? especialmente cuando concluye una clase, una actividad o un taller de sensibilización sobre género, diversidad, violencia, etc. Allí adquiere literalidad la muda (el mutismo): los varones no participan, no hablan, no sabemos lo que piensan, nosotrxs lxs docentes tampoco sabemos qué decir.

La metáfora de Pascal Quignard (2015) traza un paralelismo entre la transformación sonora y el pasaje de la niñez a la adolescencia. Esa crisis vital se evidencia en un procesamiento en género diferenciado, a los varones la voz infantil nos ha abandonado en forma de muda. Paradójicamente esta imagen no tiene el menor interés (al menos para mí) en su aspecto biológico, sino, por contrario, su plétora de sentido radica en la inscripción simbólica de la masculinización de los sujetos. El proceso de construcción viril de los adolescentes deberá atravesar nuevos ritos de pasaje, el varón adolecerá el proceso de la pedagogía de la crueldad (Segato, 2018) aprendiendo que su voz de la infancia debe ser abandonada para ser aceptado por la fratria masculina adulta.

La educación viril implica un fuerte componente represivo de las emociones. Tal como señala Badinter (1994), el varón mutilado del sistema patriarcal es un sujeto cercenado emocionalmente, los pasajes de la pubertad a la adultez son un itinerario de creación y recreación de ese sujeto viril que debe perder toda conexión con el ethos femenino de su entorno infantil. No es solo la escisión, la construcción de la diferencia audible, sino que la performance de la voz varonil es la conciencia progresiva de que los hombres detentan el derecho a la palabra y obtienen la voz de mando. Mientras este proceso acontece, en paralelo se comienzan a aprehender los usos del lenguaje que ya no serán adecuados para un varón. La nostalgia infantil, el tegumento cálido de la infancia sonora, se torna evanescente frente 
al uso adulto del lenguaje que sepulta irremediablemente los vestigios femeninos frente a la obligatoriedad de la performance viril para la reproducción de ese sujeto determinado como varón hetero cis.

\section{¿Qué varones? Masculinidad, masculinidades y lineamientos curriculares para la ESI}

La masculinidad entendida como dispositivo de poder orientado a la producción social de varones cis hetero (Fabbri, 2021) es la que identificaremos en este texto bajo la denominación "masculinidad" (en singular), es decir, aquella que refiere a los sujetos dominantes en la trama de las relaciones generizadas.

En los lineamientos curriculares del Consejo Federal de Educación de la Argentina (2008), la palabra varones es utilizada en 59 ocasiones, el término masculinidad en solo seis oportunidades y no existe mención al término masculinidades en ninguna de las páginas del documento.

La expresión varones en los contenidos curriculares de la ESI encarna el concepto de la masculinidad de modo totalizante. Si bien historiza y reflexiona en diversos pasajes sobre la masculinidad como una creación cultural inscripta dentro de las relaciones generizadas, atribuye a los varones cis la representación unívoca y absoluta de lo masculino.

La ausencia del término masculinidad(es) niega, o al menos invisibiliza, la existencia de expresiones de sujetxs diversxs que expresan las masculinidades de modos disidentes y pluriformes. Al opacar la existencia de estas otras identidades, presenta el conjunto de prácticas que encarna la masculinidad como únicamente habilitada para los varones cis. De este modo, se asume que la masculinidad es propiedad de tales sujetos y no un repertorio de conducta disponible para todos los cuerpos, lo cual "implica la cesión de un territorio político afectivo al heteropatriarcado” (flores, 2021, p. 140).

La masculinidad, como dimensión del universo curricular de la ESI, ha quedado delimitada a la expresión en singular del concepto, sin elucidar su carácter estructurante en tanto dispositivo de poder generador de varones cis hetero. Es observable cómo en todos los materiales del programa la definición de varón es homologada sin explicitación al varón cis, de allí que la masculinidad sea tácitamente pensada en ese único sentido. Para la ESI, en su currículum nulo, la masculinidad es únicamente un conjunto de prácticas cuyo uso es excluyente de los cuerpos de los varones cis. Aun cuando se la presente como resultado de una construcción cultural, se la define en singular y su modo de abordaje no logra desbordar los límites del binarismo cisgenerizado. 
Los contenidos curriculares y los cuadernos de la ESI, en tanto propuestas pedagógicas para el uso de los contenidos curriculares, expresan las limitaciones de su conceptualización en torno a la representación de los varones y las masculinidades. El universo curricular y los materiales, pese a su capacidad de dotar de un marco normativo y herramientas para la implementación de educación sexual en el ámbito escolar, representan una mirada anclada en el binarismo que invisibiliza a lxs sujetxs que expresan sus performances de género en cuerpos diversos. La masculinidad de la ESI excluye las masculinidad(es) porque solo se remite al significante varón cis, dejando por fuera a las lesbianas masculinas, a los varones trans, a las chongas, a las drag kings, no binarixs y otrxs sujetxs de cuerpos y expresiones de género disidentes que se piensan o se sienten en masculino.

Valorando las contribuciones de los lineamientos, su aporte fundamental es considerar a la masculinidad (aún en singular) como un concepto incorporado como contenido en casi todos los niveles educativos. Es imprescindible dimensionar esta contribución y su esfuerzo por esclarecer el carácter histórico-cultural de dicho constructo, pero al mismo tiempo es necesario considerar que su abordaje se centra en un tipo de análisis principalmente basado en la teoría de los roles sexuales. Tal como señala Kaufman (1997), los discursos sobre el género han tenido dificultades para liberarse de la noción, fácil pero limitada, de roles sexuales. Sin duda los roles, expectativas e ideas acerca del comportamiento apropiado sí existen, pero la esencia del concepto de género no está en la prescripción de algunos roles y la proscripción de otros. Los contenidos de la ESI no contemplan un aspecto clave de la perspectiva de género, que es colocar el foco en las relaciones de poder entre varones y mujeres ( $u$ otras identidades feminizadas) y en cómo se produce la interiorización de tales relaciones jerárquicas.

$\mathrm{Al}$ no abandonar el modelo de los roles sexuales, se universaliza el sujeto varón (niño) hetero cis, a la vez que se modela su par binario (la niña/mujer cis), sin interpelar el lugar dominante que ocupa el varón hetero cis en la trama de poder de las relaciones generizadas. Tal como expresan Morgade y Alonso (2008) la categoría supuestamente genérica de "niño" nombra en realidad una suerte de "neutro burgués, blanco, masculino y heterosexual". Las conceptualizaciones expresadas en los contenidos de la ESI no logran desafiar esa enunciación parcial del universo de la infancia y las adolescencias, excluyendo otras definiciones y otras identidades.

Ofrecer un modelo único de masculinidad como concepto obstaculiza su comprensión también como dispositivo de poder intragénero. Utilizando el concepto gramsciano de hegemonía, Connell (2003) coloca el énfasis en el ejercicio de dominación y la estructuración de las relaciones jerarquizadas que se organizan en torno a la masculinidad hegemónica o dominante. El modelo y las formas en que la masculinidad hegemónica ejercen 
La normativa legal y los contenidos generados por el programa configuran la base de lo que se entiende por educación sexual para la institución escolar en el sistema educativo argentino. En la construcción de la ley que dio origen a la ESI y en el intrincado camino que aún estamos transitando hacia su completa implementación se evidencian tensiones y se plasman con especial hondura sus concesiones, omisiones y silencios en lo referido a lxs sujetxs e identidades que se expresan en géneros y performances de género que no se ajustan al modelo cis heteronormado.

Para poder rastrear esas formas específicas que encarna la masculinidad en tanto dispositivo de poder al interior de la institución escolar se debe ir más allá de los contenidos y materiales generados por el universo normativo de la ESI y su programa.

\section{La escuela como agente en el proceso de construcción de masculinidad}

La educación en género es un proceso cultural complejo que excede las vivencias e intervenciones que se producen en el ámbito de la institución escolar, pero esta es un agente de relevancia en el proceso de producción y reproducción de las relaciones generizadas.

El surgimiento de la ley de ESI, aun con sus complejidades de implementación, explicita un currículum formal sobre el cual es posible formular críticas e impulsar agendas de transformación de su orientación. Las tensiones en torno a la ESI se enmarcan en un marco mucho más amplio que atraviesa la propia historia de la institución escolar moderna y la forma en que en ella se ha expresado el sistema sexo-género. Tal como señala Morgade (2001), en la educación formal existe desde siempre una "educación sexual" cuyo sentido primordial es preservar el orden social de género establecido. 
Más allá del análisis del plexo normativo de la ESI, es posible abismarse hacia lo que subyace de modo no formal en la vida cotidiana de la institución escolar. Uno de los elementos que permite organizar ese análisis intraescolar es el concepto de régimen de género. Con el concepto "regímenes de género" se hace referencia a las prácticas - aplicadas a todos los miembros de la institución- por las que en la escuela se construyen masculinidades y feminidades, se establecen jerarquías y se divide sexualmente el trabajo (Connell, 1985). Estos regímenes recrean órdenes de género, es decir, expectativas y tratos diferenciados, códigos de conducta, etcétera.

Si bien los regímenes de género se expresan de forma diferente en cada institución escolar, estos deben acomodarse a los límites establecidos por la cultura más amplia y a las restricciones del sistema educativo local. Según Connell (2003) el trabajo teórico sobre género nos permite organizar los diferentes componentes del régimen de género de una escuela. Cuatro tipos de relaciones están involucrados:

\section{a) Relaciones de poder}

El régimen de género orienta prácticas jerarquizadas al interior del escenario escolar. La masculinidad como dispositivo conlleva el ejercicio de prácticas y alianzas en que se plasma ese poder y que articulan las relaciones de subordinación y dominio hacia las mujeres e identidades feminizadas, pero también orientadas a definir jerarquías en la homosociabilidad.

\section{b) División sexual del trabajo}

La división sexual del trabajo no puede ser entendida al margen de la reproducción generizada de las personas. Según Butler (2016), el género y la sexualidad pasan a formar parte de la vida material. A su vez, val flores (2019) aporta el cuestionamiento a las matrices históricas de feminización de la docencia y de masculinización de la producción del conocimiento, los marcos de disputas sociales que producen performativamente estas posiciones y estratos, reproduciendo históricas formas de opresión y de control

Por su parte, Faur (2019) evidencia los mecanismos de un modo específico de "división sexual del deseo" que coloca al varón en un rol activo y hasta desenfrenado, y a la mujer como un sujeto no deseante.

\section{c) Patrones de emoción}

Arlie Hochschild (2008) utiliza el concepto "reglas del sentir" para definir este aspecto. Para esta autora, la noción hace foco en los determinantes y las bases socioculturales que definen, evalúan y manejan las emociones y sentimientos humanos. Entre las reglas del sentir más importantes en las escuelas están las relacionadas con la sexualidad. La persona (docente o estudiante) utiliza un "vocabulario de las emociones" y comprende en qué situaciones 
debe ocultar sus sentimientos en la institución y qué clase de expresiones son esperables o indeseables para el régimen de género escolar.

\section{d) Simbolización}

El dominio simbólico, que es el dominio por excelencia de la cultura, da significado y actúa por medio de un delicado mecanismo. La escuela como institución construye un imaginario de lo que significa ser varón y ser mujer. Tal patrón se plasma en una definición institucional de femineidad y de masculinidad.

El dispositivo de la masculinidad se plasma en la comunión visual, las imágenes y las figuras que forman parte de la escenografía de las instituciones escolares. En estas representaciones no solo se plasman modelos de masculinidad ideal, sino que también se juega un papel determinante en la epistemología masculinista. El modelo de la masculinidad heroica (Palermo, 2017) representa una construcción pedagógica compleja mediante la cual una personalidad se convierte en soporte de identificación colectiva con atributos inalcanzables pero estructurantes en el proceso de construcción de la identidad masculina.

Una de las características más significativas del régimen de género escolar es que, aun inscriptas en un modelo más amplio de relaciones generizadas, existen diferentes culturas institucionales. Estos modelos no son totalmente homogéneos, lo cual es particularmente relevante para las instituciones del sistema educativo argentino dada su segmentación actual.

En cuanto a la heterogeneidad de las unidades educativas es pertinente asumir los diferentes modos en que se expresa el régimen de género escolar atendiendo a la interseccionalidad para analizar las diferencias entre las comunidades educativas. Requiere un trabajo muy profundo y complejo analizar las diferencias entre las escuelas públicas mayoritariamente pobladas por lxs hijxs de las clases trabajadoras (con sus propias segmentaciones al interior del conjunto) y las orientadas a las fracciones más privilegiadas de las burguesías de los centros urbanos del país. Desde luego, a esta caracterización de clase se le debe añadir la diferenciación entre lo urbano y lo rural con las características regionales específicas de cada territorio.

El ejemplo más tangible es cómo el artículo 5 de la Ley 26150, referido al ideario institucional, ha sido utilizado fundamentalmente por las escuelas confesionales para establecer un régimen de género acorde a su marco doctrinario. Componiendo un marco interpretativo que sujeta la sexualidad al dogma católico, "feminidad y masculinidad son dones complementarios, en cuya virtud la sexualidad humana es parte integrante de la concreta capacidad de amar que Dios ha inscrito en el hombre y en la mujer" (Consejo Superior de Educación Católica [CONSUDEC], 2014, p. 66). Las escuelas católicas abrevan en las fuentes basales del sistema hetero cis 
patriarcal y construyen en su organización institucional un programa pedagógico para el sostenimiento de las relaciones de poder generizadas.

Exceptuando el carácter programático e institucional de las escuelas confesionales, es más complejo identificar en el resto de las escuelas el régimen de género como un proceso intencional y planificado. La carencia de oportunidades para la formación en servicio de lxs docentes es una de las aristas más significativas de la imposibilidad de establecer un debate explícito sobre el régimen de género en las instituciones escolares. La falta de formación y las dificultades para establecer ámbitos de intercambio entre lxs diferentes actores de la comunidad educativa fomentan un marco de desarticulación institucional que se plasma en acciones individuales reducidas a meras experiencias aisladas.

\section{Los eslóganes no dialogan}

La pregunta reiterada en las escuelas sobre qué hacer con los varones refiere a una serie de fenómenos imbricados en las dinámicas del régimen de género de la institución. La simple pregunta clama (o mejor dicho re-clama) por un horizonte impreciso de imaginarios yuxtapuestos que orientan acciones heterogéneas e incluso contradictorias lanzadas al espacio escolar de forma espasmódica e inarticulada.

Uno de los fenómenos más recurrentes cuando se intenta una intervención con varones cis en el ámbito educativo es vertebrar las acciones casi exclusivamente en relación con dos dimensiones: a) prevención y b) sensibilización.

a) La prevención como línea privilegiada para pensar la intervención con varones en las instituciones educativas parece ser una de las fórmulas más repetidas en las representaciones institucionales de por qué es necesario el trabajo con varones cis. Aun las propuestas mejor intencionadas no logran articular una conexión entre estas acciones de prevención y el régimen de género de la institución en cuestión, así como tampoco parece existir un diálogo entre este conjunto de acciones preventivas y su sustrato pedagógico. Se presenta la prevención como un modo de intervención que cuenta con gran consenso dado su pretendido efecto benefactor y su objetividad pragmática. La ESI queda también subyugada bajo este orden discursivo, lo que distorsiona su potencialidad a una mera herramienta de prevención.

La premisa de la prevención conlleva implícitamente la connotación del ejercicio potencial de la violencia. La identificación del varón cis, ya en la adolescencia e incluso mucho antes, como un potencial agresor es el imaginario que mantiene a la prevención como un pilar de las demandas de intervención con varones en edad escolar. El paradigma de la prevención está vinculado a la perspectiva del riesgo, ya sea para asociar la sexualidad 
al control biomédico, como para retomar la noción de peligrosidad social asociada a los varones jóvenes (especialmente los más pobres).

Otros imaginarios asociados giran en torno a prevenir los comportamientos asociados a la llamada "masculinidad tóxica". La utilización de esta terminología denota el carácter patologizante de conductas culturales propias del patriarcado. Esta clase de operaciones buscan aislar e individualizar fenómenos sociales asociando sus causas con trastornos mentales. De un modo más amplio, Tamar Pitch (2009) denomina a este fenómeno "patologización de la vida" cotidiana y lo vincula con la retórica de la prevención, en la cual se traslada la responsabilidad al individuo. El intento de patologizar las violencias machistas es una búsqueda de transferir el carácter estructural del fenómeno a un individuo problemático sobre el cual volcar un modelo de intervención normalizante y, de ese modo, sostener la ilusión de que es posible dar "respuestas biográficas a problemas sistémicos" (Beck, 1998).

b) Uno de los modos más frecuentes en que se pretende abordar el trabajo con varones es la llamada estrategia de "sensibilización". Esta premisa sustenta propuestas diversas (charlas con especialistas, talleres, obras de teatro, etc.) cuyo objetivo es producir algún tipo de impacto subjetivo en lxs estudiantes a quienes generalmente se dirige. Uno de los rasgos más típicos en las instituciones escolares es el carácter relativamente excepcional de la propuesta, cuyo anclaje pedagógico es poco programático e inconexo con el resto de las actividades de la institución. Da cuenta de dicho rasgo el hecho de que un gran número de estas acciones de sensibilización sea realizado por personas que no forman parte de la comunidad educativa. Dependiendo del formato, las performances adquieren un tono más académico o extensionista, en el caso de convocar a expertxs del ámbito universitario, o talleres más participativos o vivenciales, cuando se tratara de activistas o artistas que abordan la temática en un sentido amplio del término.

Las acciones de sensibilización no pueden ser analizadas desde el "currículum" de lxs disertantes, ni desde la calidad artística o las cualidades didácticas, incluso tampoco sería válido evaluarlas desde el interés genuino que pudiera suscitar la propuesta. El interrogante acerca de la pertinencia de estas acciones es de qué modo se inscribe en un proceso pedagógico orientado a dialogar con la comunidad educativa y qué impacto tiene en el régimen de género de esa institución en particular. Como señala Idoia Eizmendi (2017) las estrategias de sensibilización han terminado en un aprendizaje de lemas fáciles que ignora que asumir ciertos discursos no significa haber reflexionado sobre ellos ni haberse formado desde un punto de vista crítico. 
Se trata de colocar el acento en los procedimientos de los cuales emergen estas propuestas. Los denominados procesos de sensibilización desde arriba responden a necesidades institucionales que no son fruto del debate democrático de las comunidades educativas, sino más bien intentos de adecuación a discursos de corrección política institucional. La modalidad del "como si" o pinkwashing se basa en la reproducción de acciones supuestamente profeministas, de las cuales solo se toman eslóganes vaciados de sentido. En definitiva, estos instrumentos políticos son convertidos en meros eslóganes incapaces de establecer un vínculo dialógico, lo que propicia la continuidad de las desigualdades del régimen de género instituido.

\section{Contra-pedagogía de la crueldad, la ESI como estrategia}

Las trayectorias en que se trazan los procesos de socialización que construyen la identificación genérica de los varones cis se encuentran atravesadas por un corpus de aprendizajes significativos cuyo núcleo es la virilidad. La definición de hombría sigue funcionando como la norma según la cual se evalúan otras formas de virilidad. Siguiendo a Kimmel (1997), la definición hegemónica de virilidad es un hombre en el poder, un hombre con poder y un hombre de poder.

La antropóloga Rita Segato (2018) utiliza el término "pedagogías de la crueldad" para definir todos los actos y prácticas que enseñan, habitúan y programan a los sujetos a transmutar lo vivo y su vitalidad en cosas. En este sentido plantea como eje del análisis la relación entre crueldad y masculinidad. Educarse como sujeto viril implica recorrer un periplo que deja huellas de extrema significancia; los llamados ritos de pasaje o pruebas de hombría entre pares son el mecanismo de control a nivel capilar del dispositivo de la masculinidad en singular y las formas de aprender la praxis del ejercicio del poder sobre los propios pares. Aprehender la crueldad como mecanismo de sometimiento a lxs más débiles en la jerarquía intragénero expresa la hondura de la pedagogía que se asimila en estas prácticas y se proyecta como modo expresivo e instrumental de las violencias machistas en la adultez.

Homosociabilidad no es sinónimo de intimidad entre varones. La grupalidad varonil se sustenta en la relación entre pares como miembros de la fratría masculina, en la que se establece la complicidad corporativa. Esta vincularidad exige el cumplimiento de los mandatos de la masculinidad, entre los cuales se incluye el ejercicio de la dominación sobre los que son identificados como los sujetos más vulnerables, comenzando por el sometimiento y la violencia intragénero. 
Por oposición, la contra-pedagogía de la crueldad es definida como una contra-pedagogía del poder y, por lo tanto, "una contra-pedagogía del patriarcado, porque ella se contrapone a los elementos distintivos del orden patriarcal" (Segato, 2018, p. 17).

La posibilidad de fracturar el pacto de la fratría machista requiere un espacio de diálogo crítico, donde el malestar pueda ser abordado y se produzcan situaciones de interpelación o, como las llama Jokin Azpiazu (2017), espacios de incomodidad productiva. Sin embargo, buena parte de los eslóganes basados en la deconstrucción de la masculinidad se presentan como un proyecto de transformación reducido a los espacios personales orientados por una ideología neoliberal de la individualidad. Varias de las consignas que circulan en los discursos e imaginarios de las instituciones educativas tributan en el "voluntarismo mágico" que David Smail (2001) describe como "la religión no oficial de la sociedad capitalista contemporánea", que hace creer que la posibilidad de ser lo que se quiera está en poder de cada individuo.

Estos paradigmas también se plasman en políticas educativas tal como la educación emocional sustentada en "el desarrollo de estas capacidades socioemocionales" cuyo objetivo es implementar "la educación emocional como proceso educativo innovador" (Red Escuelas de Aprendizaje, 2019, p. 46). Ocultar la conflictividad y desplazar la responsabilidad de las condiciones en que se produce la práctica de la enseñanza-aprendizaje a la propia comunidad educativa es parte de un proceso global para individuar los fenómenos sociales. Ann Cvetkovich (2018) utiliza el concepto de "sujetos sintientes" para referir a un modelo de ciudadanía que relocaliza los procesos de subjetivación en expresiones afectivas personalizadas sin contexto alguno y que, frente al conflicto, recurre a soluciones privatizadas y ahistóricas.

Según Ahmed (2021) los guiones de género y su normatividad son a la vez guiones de felicidad que enseñan a lxs sujetxs a adaptarse a las condiciones de desigualdad y poder de las relaciones generizadas. La ponderación de la vincularidad positiva como expresión virtuosa al interior de la escuela es una inhabilitación del conflicto o el enojo como recursos expresivos válidos ante situaciones injustas o autoritarias. En esta línea, Audre Lorde (2008, p. 146) plantea que ver solo el lado positivo de las cosas "es un eufemismo que se usa para ocultar ciertas realidades de la vida cuyo honesto análisis podría resultar amenazador o peligroso para el statu quo".

En los últimos años, los escraches representaron el fenómeno más significativo en la interpelación del régimen de género de las instituciones educativas. Especialmente para el nivel secundario y superior fueron el canal expresivo de una oleada feminista que conmocionó la lógica escolar agitando demandas que desafiaban la normalidad de los escenarios 
escolares. Tal como señala Faur (2019, p. 6), "las chicas dijeron 'no es no', comenzaron un profundo proceso de revisión de los vínculos entre géneros, y cuestionaron el andamiaje de poder que construyen las instituciones escolares".

Las denuncias públicas o escraches se multiplicaron en diferentes ciudades del país, con diferentes repertorios o modalidades, y fueron realizados fundamentalmente por adolescentes, mujeres y disidencias. En diferentes escuelas e institutos de formación docente, el fenómeno expresó el hartazgo y evidenció la opresión de un régimen de género que había permitido, por omisión o acción deliberada, el encubrimiento de abusos y prácticas sexistas de diferentes actores institucionales (autoridades, docentes, estudiantes). Las denuncias habitualmente se referían a hechos puntuales, pero más allá de las personas concretas señaladas como perpetradoras, permitieron generar debate e interpelar los distintos mecanismos de encubrimiento institucional de las diversas formas de violencias machistas.

Lo singular de las reacciones de los equipos de conducción y parte del mundo adulto de las comunidades educativas es que identificaron el escrache como el problema en sí y no como una expresión (incluso cuando fuera desbordada o con ribetes punitivistas) de un historial de ocultamiento de los abusos sufridos por las estudiantes mujeres y disidencias amparado por un régimen institucional patriarcal. Retomando a Faur, en la experiencia del Colegio Nacional de Buenos Aires problematiza que la incomodidad del mundo adulto frente al punitivismo de los escraches "operó como un vidrio oscuro e impidió ver (y comprender) qué había detrás de estas manifestaciones: cómo se gestaron, cuáles fueron sus lógicas, qué respuestas ofrecieron las autoridades, qué piensan y hacen los y las docentes" (Faur, 2019, p. 7).

En este marco, centrar la mirada en los excesos o la violencia de los métodos empleados en los "escraches" ha sido una coartada frecuente para sostener los privilegios del poder androcéntrico y apelar a la negación del conflicto para no asumir formalmente la responsabilidad institucional, desplazando la culpa hacia una supuesta "conflictividad" de lxs sujetxs oprimidxs. Los intentos de las instituciones educativas por aplacar los conflictos y restablecer el "buen clima" en las aulas es un llamado a la complacencia y a la aceptación acrítica. Como señala Charlote Perkins Gilman (2021): "la comodidad y la felicidad son muy probablemente el resultado de un largo proceso de adaptación".

Justamente, en el vértice opuesto se presenta la emergencia de las nuevas demandas, las voces que interpelan e incomodan el régimen de género y las formas en que se expresan las relaciones generizadas en el ámbito de la institución escolar. Los feminismos y las identidades que expresan disidencias al interior de nuestras instituciones agitan la estabilidad de 
ese orden androcéntrico y hetero cis normativo para "rehusarse a seguir la corriente, rehusarse a ocupar el lugar en que se nos ubica, equivale a ser consideradas personas problemáticas, personas que causan incomodidad" (Ahmed, 2021, p. 151).

Por ello, es necesario sostener la incomodidad, dotarla de sentido, reconocer las voces que gritan e interpelan lo establecido y también los silencios, las palabras que aún no pueden ser nombradas, los enojos y la falta de mecanismos para expresar lo que aún no se puede procesar desde las identidades masculinas. La afectividad como dimensión de la ESI es un habilitante para pensar un proceso de transformación que construya ese horizonte político que significa una contra-pedagogía de la crueldad. Ensanchar el campo interpretativo para acompañar los procesos de las masculinidades en la infancia y especialmente en las adolescencias y permitirnos como adultos profundizar en los repertorios sensibles del malestar, sin proponer procesos alquímicos ni soluciones terapéuticas individuales. La afectividad puede ser sostén para el aprendizaje del malestar masculino y la incomodidad puede tornarse productiva cuando todo ese proceso se inscribe en un proyecto colectivo.

\section{Régimen de género y el derecho a aparecer}

Las instituciones educativas, pese a desplegar un régimen de género concordante con el sistema sexo-género, no son escenarios sociales meramente reproductivos. La escuela es un espacio social en el cual se reafirman las prácticas de los sujetos sociales y las identidades codificadas por el saber dominante. Sin embargo, el escenario escolar es también un campo de disputa donde lo subalterno emerge e impulsa nuevas y vigorosas conflictividades. En esta contradictoria duplicidad de la institución como ámbito de reproducción y a la vez como campo de la lucha simbólica,

la escuela contrapone, por un lado, el discurso hegemónico que sostiene la norma blanca, masculina, heterosexual y cristiana; $y$, por el otro, discursos plurales, provenientes de grupos sociales no hegemónicos que luchan por hacerse reconocer, rompiendo las barreras a las que fueron históricamente sometidos (Lopes Louro, 2018, p. 96).

Tal como sugiere la autora, la escuela y el currículo están inmersos en la dinámica de esta batalla simbólica y por ello puede alterar la configuración de la lucha.

Eleonor Faur (2019) nos recuerda que las transformaciones en el universo cultural sexo-genérico son lentas, pero además polirrítmicas. "Coexisten, como en un palimpsesto, miradas revolucionarias y miradas 
conservadoras y no todos ni todas construyen sus imaginarios en sentidos similares" (s. p.).

Los conflictos al interior de las instituciones educativas evidencian el acceso de nuevas identidades que pugnan por transformar lo instituido. Estos sujetxs están haciendo visibles ciertas reclamaciones sobre el derecho a ser reconocidos y a poder llevar una vida vivible. El derecho a aparecer es el concepto que utiliza Butler (2017) para referir a estos procesos. La autora plantea que esta también es una forma de generar reivindicaciones en la esfera pública, ya sea a través de una radio abierta, de una asamblea en la plaza, de una marcha por el centro de la ciudad, o de una revuelta en los arrabales de la metrópolis. Desde la perspectiva de Butler, lo más importante no es el poder que cada uno tiene y que le faculta para actuar, sino el propio impulso a la acción, entendiendo el actuar como acción enlazada a dos conceptos claves: performatividad y precariedad.

Así es como yo entiendo la performatividad, y esta es también una de las formas de actuar contra y desde la precariedad. La precariedad es una categoría que engloba a mujeres, queers y personas transgénero, a los pobres, los discapacitados y los apátridas, pero también a las minorías religiosas y raciales. Es, pues, una condición social y económica, pero no una identidad (efectivamente, trasciende todas estas clasificaciones y produce alianzas potenciales entre los que no se reconocen como miembros de una misma categoría). (Butler, 2017, p. 63)

La performatividad de género presume un campo de aparición para el género y un marco de reconocimiento que le permite mostrarse en sus diversas formas. Desde luego, este es un territorio de disputa ya que el campo está regulado por normas de reconocimiento que son jerárquicas y excluyentes. Por ello, la performatividad de género está vinculada con las acciones y las luchas en que lxs sujetxs pueden llegar a ser reconocidxs. La precariedad es una categoría que engloba a diferentes identidades atravesadas por la vulnerabilidad y la opresión, las acciones performativas producen alianzas potenciales más allá del género.

No es casual que los escenarios de mayor emergencia de demandas e impugnaciones se den en el marco de procesos de revueltas estudiantiles. Allí se vinculan repertorios históricos de las luchas del colectivo estudiantil y docente, como las tomas de escuelas, asambleas, cortes de calles, sentadas, movilizaciones, ocupaciones de oficinas públicas, que ahora también se resignifican con nuevas demandas propias de una agenda feminista y de la diversidad. De este modo, el repertorio de protesta de lxs colectivxs estudiantiles puede emerger en torno a demandas limitadas ligadas a necesidades edilicias (como ausencia de calefacción, falta de aulas, etc.) o de 
recursos básicos (como cupos para el Servicio Alimentario Escolar, SAE), y ser asimismo un espacio propicio para el surgimiento de demandas ligadas al régimen de género de la institución. Complementariamente, una protesta, un escrache por situaciones de violencia de género, también puede promover otro tipo de demandas (falta de presupuesto para cubrir cargos en los Equipos de Orientación Escolar (EOE), visibilizar la no implementación de la ESI, etc.). Allí se evidencia, que la congregación pública cumple una función expresiva que es anterior a (y va más allá de) cualquier demanda o manifestación que se pueda plantear inicialmente.

Estos fenómenos no se producen en contextos aislados. Las profundas y recurrentes crisis capitalistas del siglo XXI agudizan necesidades que se imbrican en las desigualdades de género, de clase, de raza. La interseccionalidad de las demandas es una marca epocal, porque evidencia la profundidad de la crisis y las diferentes esferas en que esta se manifiesta. El régimen de género de las escuelas es el correlato de un momento histórico en que los movimientos pendulares entre avances y retrocesos, entre transformación y reacción, se evidencian y plasman su correlato en todas las instituciones.

Frente al impulso de las demandas feministas y de los movimientos LGBTIQ+ y su capacidad de expresar una agenda significativa para una gran parte de la población y especialmente de la juventud, la escuela se transforma en una caja de resonancia de estas nuevas demandas, interpelaciones y disrupciones. Cómo la institución procesa esas nuevas demandas, aloja o expulsa a lxs sujetxs que irrumpen en su escenario y, particularmente, cómo maneja los cambios en la performatividad masculina y sus diversas expresiones son algunos de los desafíos más estimulantes que atraviesa la implementación de la ESI en esta etapa.

\section{Referencias}

Ahmed, Sara (2021). La promesa de la felicidad. Una crítica cultural al imperativo de la alegría. Buenos Aires: Caja Negra.

Azpiazu Carballo, Jokin (2017). Masculinidades y feminismo. Barcelona: Virus.

Badinter, Elisabeth (1994). XY. La identidad masculina. Bogotá: Norma.

Beck, Ulrich (1998). La sociedad del riesgo: hacia una nueva modernidad. Barcelona: Paidós.

Burin, Mabel y Meler, Irene (2000). Género: una herramienta teórica para el estudio de la subjetividad masculina. En Varones. Género y subjetividad masculina. Buenos Aires: Paidós.

Butler, Judith (2017). Cuerpos aliados y lucha política. Hacia una performativa de la asamblea. Buenos Aires: Paidós. 
Cvetkovich, Ann (2018). Un archivo de sentimientos. Trauma, sexualidad y culturas públicas lesbianas. Barcelona: Bellaterra.

Connell, Raewyn (1985). Teachers' work. Sydney: Allen y Unwin.

Connell, Raewyn (2003). Masculinidades. México D. F.: UNAM.

Consejo Superior de Educación Católica [CONSUDEC] (2014). Aportes para la implementación del Programa de Educación Sexual Integral. Buenos Aires: Santillana.

Eizmendi, Idoia (2017). Sobre políticas feministas para hombres. En Jokin Azpiazu Carballo, Masculinidades y feminismo. Barcelona: Virus.

Fabbri, Luciano (2021). La masculinidad incomodada. Rosario: UNR/Editora-Homo Sapiens.

Faur, Eleonor (2017). Mujeres y Varones en la Argentina de hoy. Géneros en movimiento. Buenos Aires: Siglo XXI.

Faur, Eleonor (2019). Del escrache a la pedagogía del deseo. Revista Anfibia. http://revistaanfibia.com/cronica/ del-escrache-la-pedagogia-del-deseo/

flores, val (2019). ¿Es la práctica pedagógica una práctica sexual? Umbrales de la imaginación teórica y erótica. Descentrada, 3. https://doi. org/10.24215/25457284e068

flores, val (2021). Con luz propia. Una posible figuración para las masculinidades lésbicas. En Luciano Fabbri (comp.), La masculinidad incomodada. Rosario: UNR/Editora-Homo Sapiens.

Halberstam, Judith (2008). Masculinidad femenina. Madrid: Egales.

Hochschild, Arlie (2008). La mercantilización de la vida íntima. Apuntes de la casa y el trabajo. Madrid: Katz.

Kaufman, Michael (1997) Las experiencias contradictorias de poder entre los hombres. Masculinidad/es. Poder y Crisis, 24.

Kimmel, Michael (1997). Homofobia, temor, vergüenza y silencio en la identidad masculina. Masculinidad/es. Poder y crisis, 24.

Lopes Louro, Guacira (2018). Los estudios feministas, los estudios gays y lésbicos y la teoría cuir como políticas de conocimiento. En Pedagogías transgresoras II. Sauce Viejo: Bocavulvaria Ediciones.

Lorde, Audre (2020). Los diarios del cáncer. Madrid: Ginecosofia.

Ministerio de Educación-Presidencia de la Nación Argentina (2008). Consejo Federal de Educación. Lineamientos curriculares para la Educación Sexual Integral. https://www.argentina.gob.ar/sites/ default/files/lineamientos_0.pdf

Morgade, Graciela (2001). Aprender a ser mujer, aprender a ser varón: relaciones de género y educación. Esbozo de un programa de acción. Buenos Aires: Noveduc. 
Morgade, Graciela y Alonso, Graciela (2008). Cuerpos y sexualidades en la escuela. De la "normalidad" a la disidencia. Buenos Aires: Paidós.

Palermo, Hernán (2017). La producción de la masculinidad en el trabajo petrolero. Buenos Aires: Biblos.

Perkins Gilman, Charlotte (2021). The home, its work and influence. New York: The Co-Operative Press.

Pitch, Tamar (2009). La sociedad de la prevención. Buenos Aires: Ad Hoc. Quignard, Pascal (2015). La lección de música. Madrid: Funambulista S. L. Red de Escuelas de Aprendizaje (2019). Informe de evaluación. Dirección General de Cultura y Educación de la Provincia de Buenos Aires, Argentina. http://www.abc.gov.ar/sites/default/files/web_ red_de_escuelas.pdf

Rubin, Gayle (1996). El tráfico de mujeres: notas sobre la economía política del sexo. En Marta Lamas (comp.), El género: la construcción cultural de la diferencia sexual (pp. 35-96). México: PUEG.

Segato, Rita (2018). Contrapedagogías de la crueldad. Buenos Aires: Prometeo.

Smail, David (2001). Why therapy doesn't work and what we should do about it. London: Robinson. 